\title{
Prioritization and selection of Electrical Vehicle Systems to improve its performances: an AHP approach
}

\author{
Emilio Larrodé \\ Full Professor, Department of Mechanical Engineering. Transportation Division, \\ University of Zaragoza, Spain \\ Victoria Muerza \\ Researcher, Department of Mechanical Engineering. Transportation Division, University \\ of Zaragoza, Spain \\ Juan- Bautista Arroyo \\ Professor, Department of Electrical Engineering, University of Zaragoza, Spain
}

\section{SUMMARY}

In the study of the improvement of urban transport in terms of energy efficiency and environmental improvement, one of the best options is the use of electric vehicles for both passengers and freight distribution.

Depending on the type of transport operation to be performed, it is necessary to select the most appropriate vehicle that meets the necessary requirements, so that the result is an improvement in energy efficiency and low environmental impact.

It is therefore necessary to design architectures for electric vehicles, specially adapted to the different scenarios in which are to be used, and where they can optimize the transport operation in both reducing energy consumption and reducing emissions, maintaining a cost competitive with current vehicle operation.

The electrical vehicles (EV) are composed of different systems. A typical EV structure involves five subsystems: (i) drive system, (ii) power system, (iii) control system, (iv) vehicle structure and (v) auxiliary systems. This paper focuses on the development of a multicriteria decision procedure based on the use of the Analytic Hierarchy Process (AHP), to prioritize among the five vehicle systems, in which the design efforts should be guided to improve the vehicle performances in a given scenario of vehicle use.

\section{INTRODUCTION}

Electric vehicles are seen by many as the cars of the future due they are high efficient, produces no local pollution, are silent, and can be used for power regulation by the grid operator (Schaltz, 2011).

An EV uses one or more electric or traction motors for propulsion and can be separated into three groups, based on how and where the electricity is produced (Faiz et al., 1996): (i) 
Vehicles relying on continuous electric supply from an off-board generation system, e.g. trolley buses supplied by overhead wires, as well as most electric rail transportation systems; (ii) Vehicles relying on stored electricity from an off-board generation system, e.g. batteryelectric vehicles, and vehicles using other energy storage media such as flywheels (zeroemission vehicles); and (iii) Vehicles relying on on-board electric generation to supply their needs, including series electric hybrids, parallel electric hybrids, and fuel-cell electric vehicles.

Modeling an electric vehicle is a very complex task as it contains many different components, where sizing of the vehicle must consider the demands of career and regulations of the European Union, adapted to different scenarios of use. A typical EV structure involves five subsystems: (i) drive system, (ii) power system, (iii) control system, (iv) vehicle structure and (v) auxiliary systems.

This paper shows a multicriteria procedure based on the Analytic Hierarchy Process (AHP) to prioritize and select the most suitable configuration of the five vehicle systems to improve the vehicle performances in a given scenario of vehicle use.

\section{VEHICLE CONFIGURATION}

As stated above, modeling an EV is a highly complex problem, and the configuration of the vehicle has to be adapted to the different scenarios of use. The major components of an EV include two subsystems (Salem, 2013): the electric motor and the vehicle systems which include an electric machine as drive system, electrical energy sources, control systems as a central control, and power converter as a device that converts electrical energy source with variable needs of the electric vehicle by switching devices (see Figure 1). More recently, Larrodé et al. (2016), as a part of the development of the racing electric vehicle "Zytel-Zero", developed in the laboratories of the Aragón Institute for Engineering Research (i3A) of the University of Zaragoza described their research according to the work done into the vehicle in five blocks: the drive system, the power system, the control system, the vehicle structure and auxiliary systems (see Figure 2). This paper follows the same vehicle structure and considers the same five subsystems.

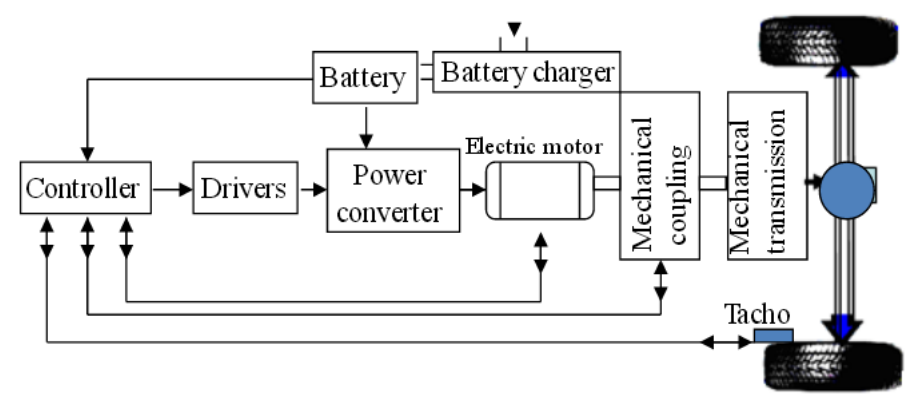

Fig. 1- Major components of an electric vehicle (Salem, 2013) 


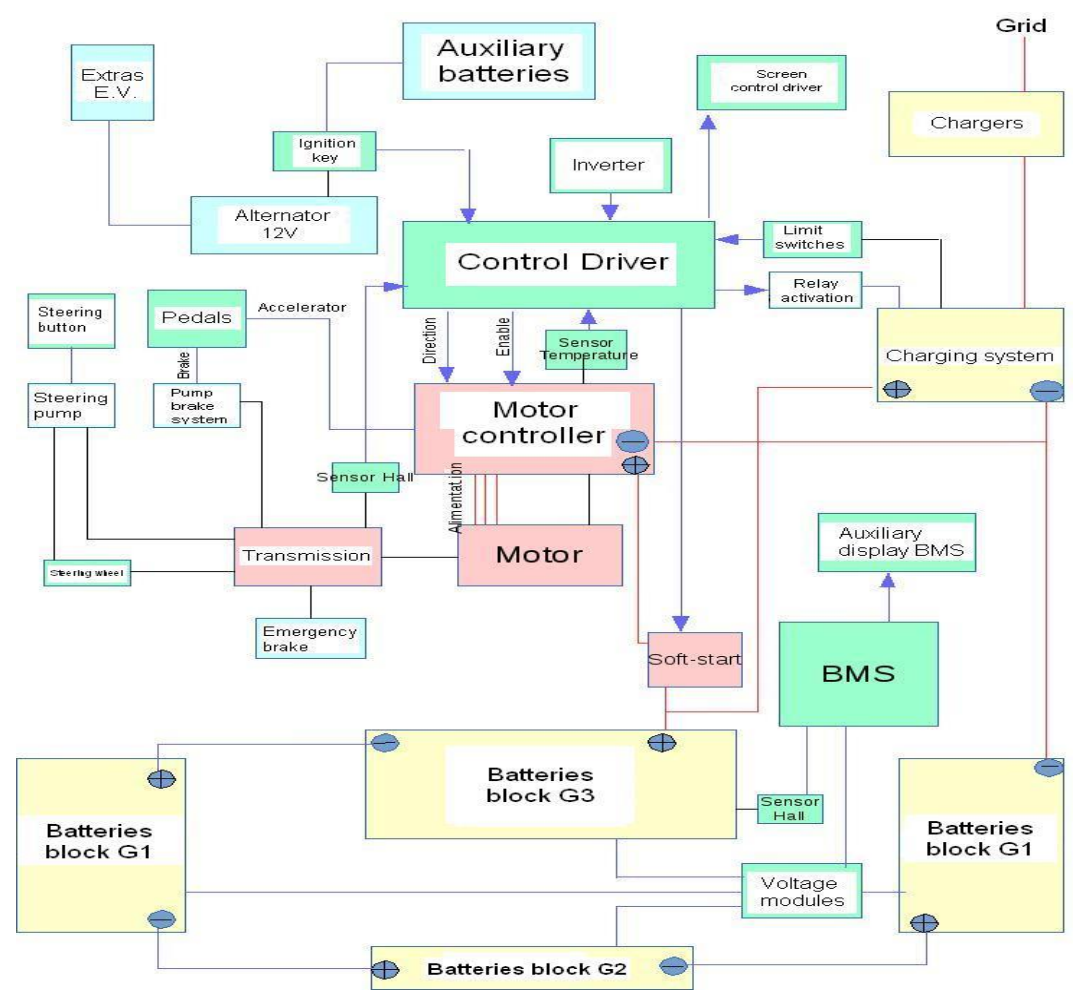

Fig. 2 - "Zytel- Zero" Vehicle scheme (Larrodé et al., 2016)

\subsection{Drive System}

This subsystem includes all the necessary elements for the movement of the vehicle: the powertrain, transmission, suspension, steering and rolling of the vehicle.

\subsection{Power System}

The Power System of an EV refers to the on- board energy generation and the energy storage. There are many structures of multi energy sources for EVs, e.g. batteries; power battery and super capacitor; fuel cells, auxiliary power batteries and super-capacitor; fuel cells and super capacitor; fuel cells and power battery (Jinrui et al., 2006).

\subsection{Control System}

The control and monitoring of the different variables of the system is needed for a proper interaction between the user and the vehicle. The control system is divided into two parts: (i) the controller, which controls the state variables of the vehicle and, (ii) the battery management system (BMS) to control the level and condition thereof. The main functions of the vehicle controller are (Wang et al., 2015): Drive torque control, the braking energy optimization control, the vehicle energy management, the maintenance and management of the network, fault diagnosis and processing, and the vehicle condition monitoring.

\subsection{Vehicle Structure}

The two main set of parts of the vehicle structure are the body and the chassis, which depend on the functionality (freight or passengers). 


\subsection{Auxiliary Systems}

The auxiliary systems are composed by a collection of related automotive Electrical components that interact with the main car systems and components to support its functionality. These systems reduce the driving range since they are using battery power, and are related with Security Systems, Comfort Systems, Lighting Systems and Information Systems.

\section{PRIORITIZATION AND SELECTION OF THE ELECTRICAL VEHICLE SYSTEMS: A MULTICRITERIA ANALYSIS}

\subsection{The Analytic Hierarchy Process (AHP)}

The Analytic Hierarchy Process (AHP) is a multi-criteria approach commonly used in decision making processes. It allows solving highly complex problems characterized by the existence of multiple scenarios, actors and criteria (both tangible and intangible). The general steps of the method are (Saaty, 1994): (i) Modeling: hierarchy construction of the problem, identifying the goal, the relevant criteria, the sub-criteria present in each criterion, the actors and alternatives. The resulting hierarchy must be complete, representative, nonredundant and minimalist; (ii) Valuation: Based on the judgments made by the decision maker, paired comparisons are established between the elements of the hierarchy by using the fundamental scale of Saaty (Saaty, 1980). In comparison, the element that shows, to a lesser extent or degree the characteristic under study, is taken as a reference, and a numerical value is given about the times the greater includes, contains, dominates or is more preferred than the least with regard to the studied attribute; (iii) Prioritization and synthesis: local and global priorities of the hierarchy elements are determined. Later on, priorities are grouped through the principle of hierarchical composition with the objective to offer an overall assessment of the available alternatives; and (iv) Sensitivity analysis: system stability through tests to search for the best alternative regarding different changes in the criteria priorities.

This method performs to main contributions (Barba-Romero and Pomerol, 1997): detect and accept, within certain limits, the inconsistency of decision makers, and (ii) allows employ naturally a hierarchy of criteria, which cannot make methods that require global comparisons of the alternatives. However, AHP has received some criticism, e.g. due to the method laboriousness derived from the need to compare all possible pairs of elements (Takeda et al, 1987) that lead to errors and inconsistencies.

\subsection{Design of the decision model}

AHP has previously been used in the EV research, more specifically in the energy supply network (Li and Chang, 2011), and the evaluation of different elements (Lin et al., 2006; Ho and Huang, 2014). More recently, Larrodé et al. (2016) presents a multicriteria approach based on AHP focused on the electrification of a vehicle. 
This paper goes ahead and proposes the prioritization and selection of the five EV subsystems (seen as the alternatives of the model: A1- Drive System; A2- Power System; A3- Control System; A4- Vehicle Structure; A5- Auxiliary Systems) to improve the vehicle performances in a given scenario of vehicle use. The chosen scenarios are three: (i) S1Urban vehicles; (ii) S2- Road vehicles; and (iii) S3- Delivery Van vehicles.

Urban vehicles are characterized for its small size, low speed performance, low consumption and low weight; Road vehicles characteristics include speed, power, comfort and autonomy; the main characteristics of Delivery Van vehicles, used in urban environments include big size, range necessity, low speed performance and high weight.

The hierarchy (Figure 3) was built according to economical (cost and consumption), environmental (emissions and recyclability) and technical (traction, range and load capacity) criteria. The local priorities were obtained by using the eigenvector method. The global priorities were derived by means of the hierarchical composition principle. All pairwise matrices have acceptable inconsistencies $(\mathrm{CR}<0.10)$. The values of the local, global and total priorities were obtained by using of the Expert Choice Software, version 11.1 (see Figure 4 (a), (b) y (c)).

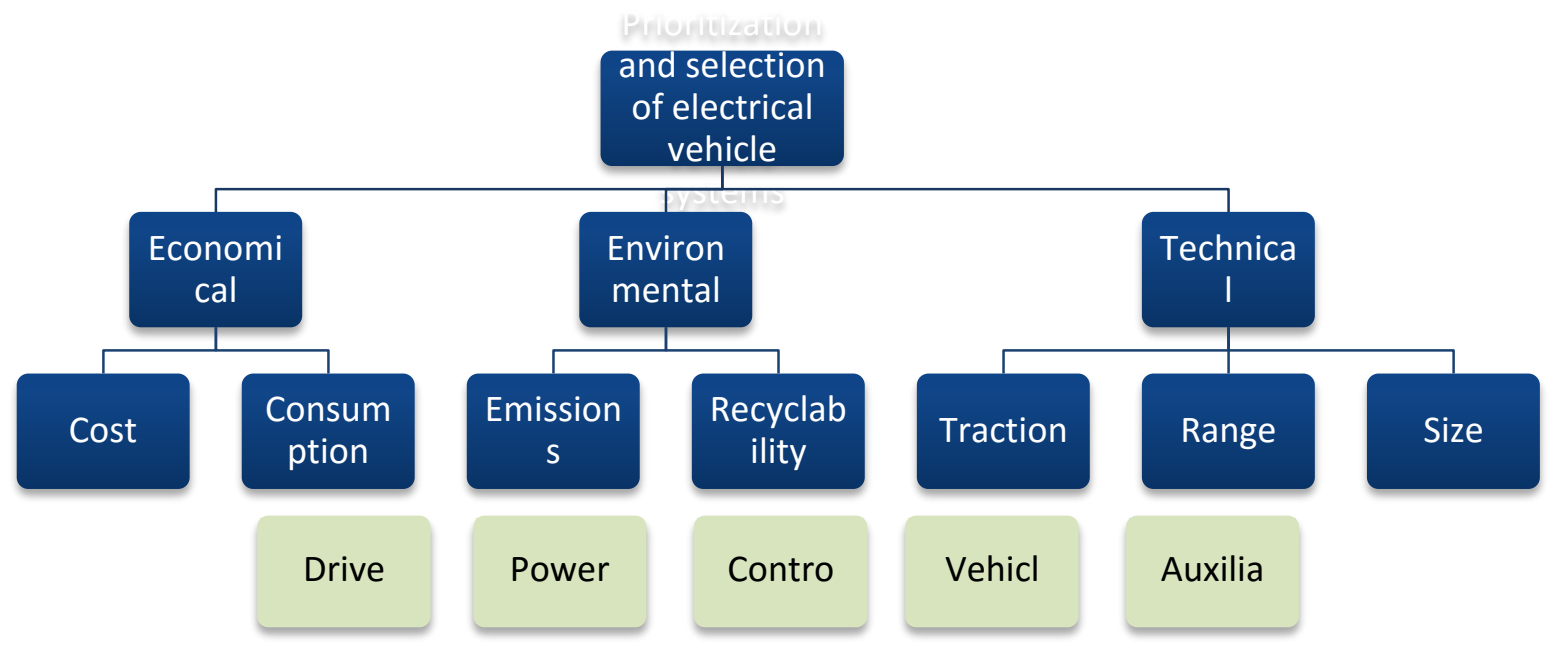

Fig. 3 - Structure of the problem

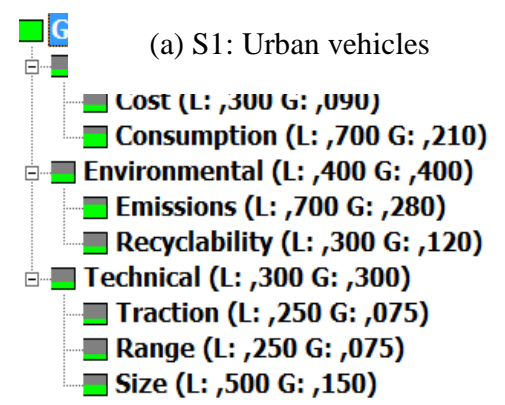

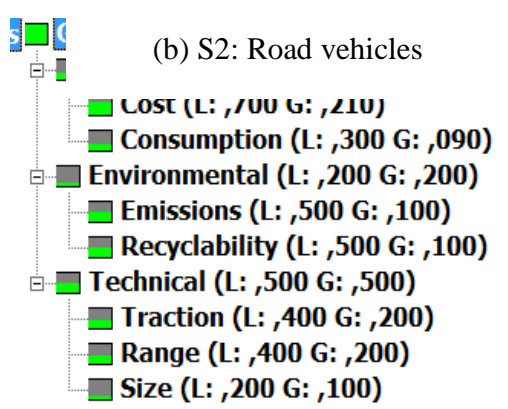

(c) S3: Delivery Van vehicles
Cost (L: ,juU G: ,100)
$\square$ Consumption (L: ,500 G: ,100)
$\square$ Environmental (L: ,200 G: ,200)
$\square$ Emissions (L: ,600 G: ,120)
$\square$ Recyclability (L: ,400 G: ,080)
$\square$ Technical (L: ,600 G: ,600)
$\square$ Traction (L: ,300 G: ,180)
$\square$ Range (L: ,350 G: ,210)
$\square$ Size (L: ,350 G: ,210) 


\section{Fig. 4 - Local and global priorities for the different scenarios}

\subsection{Comparison of different scenarios}

Figure 5 presents a comparison of the total priorities for the five alternatives in the studied scenarios. The ranking of alternatives shows the Drive System is the preferred to improve the vehicle performances in an Urban vehicle (A1>A3>A4>A2>A5) and Road vehicle use $(\mathrm{A} 1>\mathrm{A} 4>\mathrm{A} 2>\mathrm{A} 3>\mathrm{A} 5)$, while in a Delivery Van Vehicle the preferred alternative is the Vehicle Structure $(\mathrm{A} 4>\mathrm{A} 2>\mathrm{A} 1>\mathrm{A} 3>\mathrm{A} 5)$.

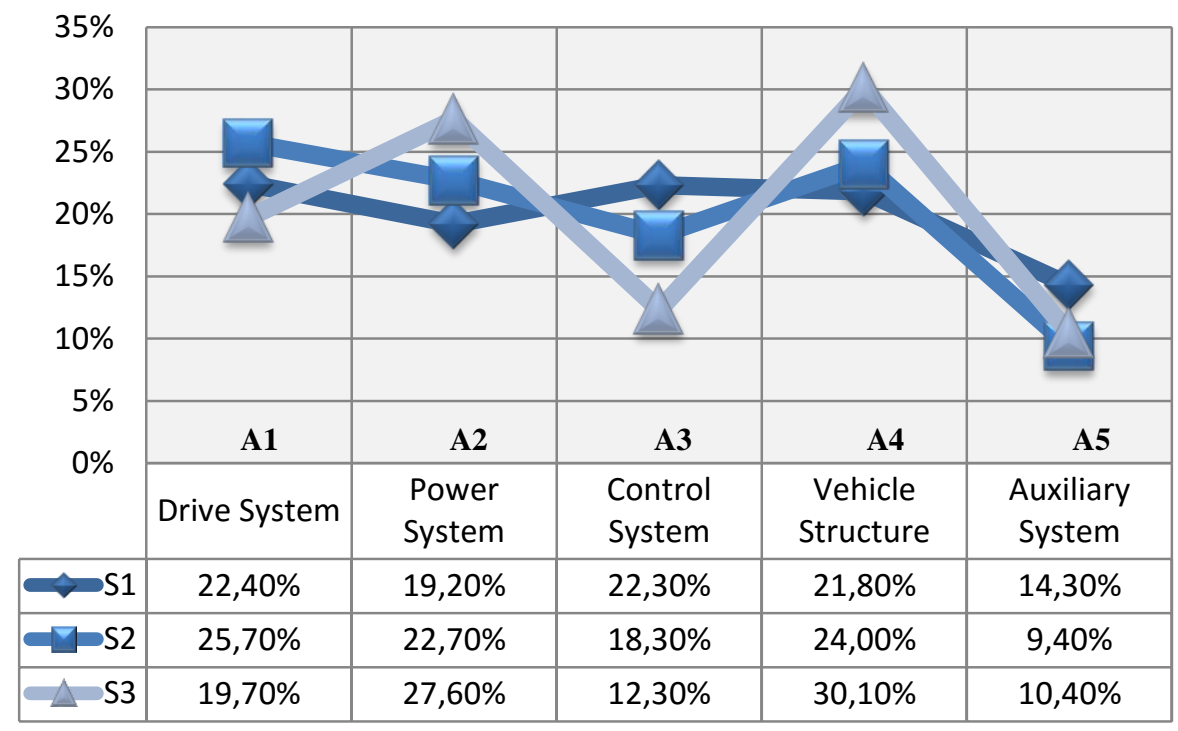

Fig. 5 - Final priorities of the alternatives analyzed for the different scenarios

Expert Choice includes different sensibility graphic tools for supporting the study of the results stability. The performance graphic (Figure 6) gives information on the total priorities of the alternatives and their global behaviour with respect to the criteria. It can be seen there are two alternatives (A1 and A4) that dominate the rest of alternatives in the three scenarios, and the best alternative, the Drive System (A1) dominates the other four alternatives in the Economical and Technical criteria (both in S1 and S2), while the Vehicle Structure dominates the other four alternatives in all criteria in S3.

By introducing changes in the criteria weight, it can be provoked a rank reversal for the best alternative. For example, in S1 it is necessary to increase the weight of the Environmental criterion by $4 \%$, for A3 to be the best alternative. In S2 it is necessary to increase the weight of the Environmental criterion by $9 \%$, for A4 to be the best alternative. Finally, in S3, rank reversal is unlikely due to the radical changes to be produced even increasing the weight of the different attributes by $100 \%$.

This analysis shows the ranking of alternatives in S3 is very robust, and 'Vehicle Structure' (A4) is the system that has a major influence for improving the performance of an EV. 
However, the ranking of alternatives in S1 and S2 could change by increasing the weight of the Environmental criterion in a low range (less than $10 \%$ ).
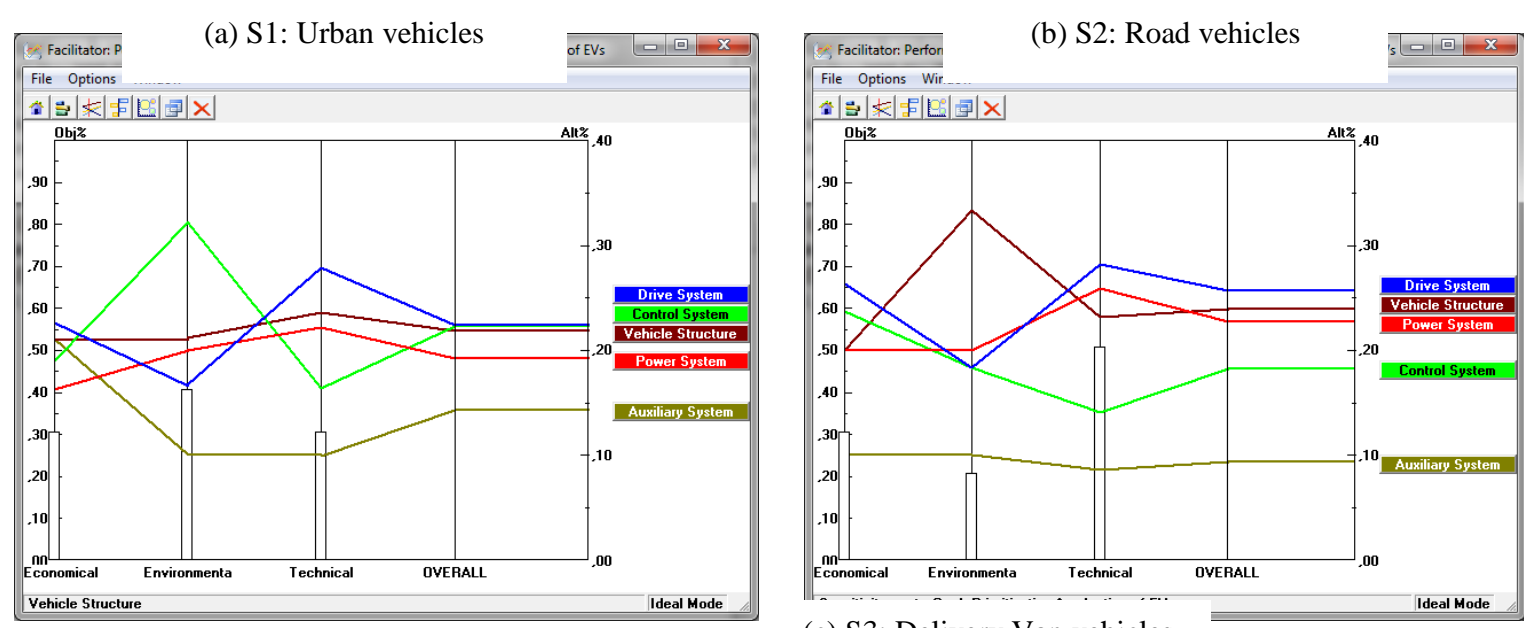

(c) S3: Delivery Van vehicles

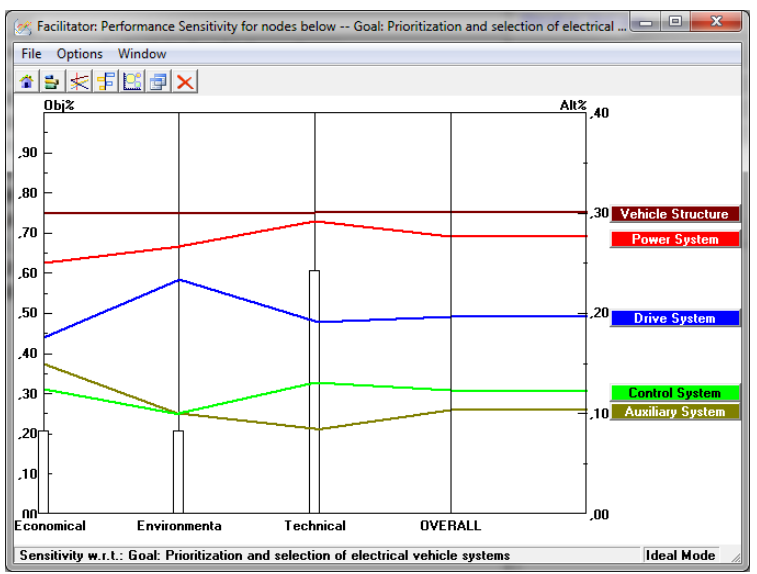

Fig. 6 - Sensibility analysis of the global model: performance graphic

\section{CONCLUSIONS}

The objective of this work was to develop a multicriteria procedure based on AHP to prioritize among the vehicle systems in which the design efforts should be guided (Drive System, Power System, Control System, Vehicle Structure and Auxiliary Systems) to improve the vehicle performances in a given scenario of vehicle use. The scenarios studied were three: Urban vehicles, Road vehicles and Delivery van vehicles.

The results shows that for Urban vehicles (S1), all systems present similar importance according its weights in the decision model, moreover the auxiliary system is more relevant in this type of vehicle than others. Road vehicles (S2) shows the system that most influences the vehicles performance is the Drive System, while for Delivery Van vehicles (S3) is more important the structure system. The sensibility analysis has shown that the ranking of 
alternatives is very robust in S3, being the Vehicle Structure the most preferred in all cases, while in S1 and S2 the ranking could vary with small changes in the weight of the environmental criterion (less than $10 \%$ of the initial value).

\section{REFERENCES}

BARBA-ROMERO, S. and POMEROL, J. (1997). Decisiones multicriterio. Fundamentos teóricos y utilización práctica. Servicio de Publicaciones de la Universidad de Alcalá.

CHAN, C. C., BOUSCAYROL, A. and CHEN, K. (2010). Electric, hybrid, and fuel-cell vehicles: Architectures and modeling. IEEE Transactions on Vehicular Technology, 59(2), pp. 589- 598.

FAIZ, A, WEAVER, C. S., and WALSH, M. P. (1996). Air Pollution from Motor Vehicles: Standards and Technologies for Controlling Emissions. World Bank Publications, Washington, D. C.

HO, J. C. and HUANG, Y.-H. S. (2014). Evaluation of Electric Vehicle Power Technologies. 2014 Proceedings of PICMET '14: Infrastructure and Service Integration.

JINRUI, N., FENGCHUN, S. and QINGLIAN, R. (2006). A Study of Energy Management System of Electric Vehicles. Vehicle Power and Propulsion Conference (VPPC), 2006 IEEE.

LARRODÉ, E., FRAILE, A. and ARROYO, J. B. (2016). Design and systems integration in the electrification of an electric vehicle for long distance travel. Hierarchical multicriteria analysis for designing the vehicle architecture. Advanced Microsystems for Automotive Applications 2015, pp. 211-222.

LI, B. and CHANG, X. (2011). Application of analytic hierarchy process in the planning of energy supply network for electric vehicles. Energy Procedia, 12, pp. 1083-1089.

LIN, C., MENG, X., WANG, Z. and SUN, F. (2006). Study on the general performance evaluation of the traction battery for EVs. Gaojishu Tongxin/Chinese High Technology Letters, 16(9), 929-933.

SAATY T.L. (1980). The Analytic Hierarchy Process: Planning, Priority Setting and Resource Allocation. McGraw-Hill, New York.

SAATY, T. L. (1994). Fundamentals of decision making and priority theory with the Analytic Hierarchy Process. Pittsburgh, PA: RWS Publications.

SCHALTZ, E. (2011). Electrical Vehicle Design and Modeling, Electric VehiclesModelling and Simulations, Dr. Seref Soylu (Ed.), ISBN: 978-953-307-477-1, InTech, Available from: http://www.intechopen.com/books/electric-vehicles-modelling-andsimulations/electrical-vehicle-design-andmodeling

TAKEDA, E., COGGER, K. O. and YU, P. L. (1987). Estimating criterion weights using eigenvectors: A comparative study. European Journal of Operational Research, 29(3), pp. $360-369$.

WANG, H., SUN, T., ZHOU, X. and FAN, Q. (2015). Research on the Electric Vehicle 
Control System. International Journal of u- and e-Service, Science and Technology, 8(8), pp. 103-110. 